\title{
THE RESEARCH ON THE TECHNOLOGICAL SYSTEM IN DEEP HOLES CHAMBERING PROCESS
}

\author{
Antoni Świć', Oleg Draczew², Tomasz Szot³ ${ }^{3}$, Sadi Majdalawi \\ 1 The Institute of Information Technology Systems, Lublin University of Technology, ul. Nadbystrzycka 36, \\ 20-618 Lublin, Poland, e-mail: a.swic@pollub.pl \\ 2 Togliatti State Technical University, Russia \\ 3 The Institute of Information Technology Systems, Lublin University of Technology, Poland
}

Received: 2012.10.03

Accepted: 2012.11 .14

Published: 2012.12.21

\begin{abstract}
Two-mass model of bitool chambering was introduced. Build on its basis mathematical model of deep holes chambering was used to conduct numerical analysis of the system. By optimizing parameters of machine-fixture-part-tool system one can reduce the time of transitory processes, increase dynamic rigidity and decrease tremblings level during deep hole chambering, what allows to increase their accuracy and machining efficiency.
\end{abstract}

Keywords: deep holes chambering, technological system, mathematical model.

\section{INTRODUCTION}

In technological system of deep holes chambering two sub-systems were defined: part-support and tool-support. Even though the elastic system of a machine-tool is a system with numerous interrelations and masses, a change of shape while undergoing machining of a part is defined mainly by these two forming systems. Machining force is replaced with an external force which changes in a sinus or linear manner. These models are implemented in order to evaluate natural frequencies of the system: machinetool - mounting - instrument-tool (OUPN) or the whole system [6].

In the process of chambering, statistical vibrations and displacements towards axis y have got the largest influence upon precision.

Research conducted in the dynamic description of a machine-tool's elastic system $[3,4,5]$ (a part is fixed in a three-jaw chuck, rear chuck is a swivel-type) indicated that altering the basic point of application of an interfering influence does not change the qualitative character of amplitude-phase-frequency curves characteristics
(ChAFC). As a consequence, as regards interferences, it is acceptable to describe the OUPN system in the linear form. An elastic system may be presented as a sum of dynamic elements whose behavior can be described by means of a quadratic equation.

Force interactions influencing a technological system can be divided into external kinematic interferences which entail forced oscillations and internal interferences conditioned by machining process- these depend on machining parameters and the geometry of the semi-manufactured product.

Research indicated that periodic force which changes in a sinusoid manner, caused by the imbalance of the revolving part, is the fundamental external interference.

The second group of forces brings about self-exciting oscillations. In case of their lack, the process of machining is regarded as stable, thus it can be described by means of a quasistatic characteristic. It is the proportion of constants of the machining time $\left(T_{s k}\right)$ to elastic system time $\left(T_{u s}\right)$ where $T_{s k}<<T_{u s}$. Such description is used in the analysis of forced oscillations where the 
elastic system and machining process are stable. Finding analytic relationships leads to defining resonance zones.

OUPN is a closed system because the amplitude of vibrations of the part is the function of the tool's vibrations and it changes depending on machining conditions.

Two-mass models do not take into account:

- influence of forces on an individual group and interreactions of individual groups,

- influence of individual group's parameters on the whole system.

\section{TWO-MASS MODEL OF DEEP HOLE CHAMBERING}

The designed model of double parting-off tool chambering which takes into account the influence of basic groups, machining process and external forces of the system is shown on Fig. 1. The model presents two point masses $m_{1}$ and $m_{2}$ with stationary base mounted by means of springs and absorbers with linear characteristics and rigidity and absorbency ratios respectively $\left(k_{1}\right.$ and $k_{2}, \beta_{1}$ and $\left.\beta_{2}\right)$. Interreactions of masses in machining process are described by the linear characteristic with rigidity ratio $k_{\mathbb{R}}^{A}$ on the first parting-off tool and $k_{\mathfrak{p}}^{B}$ on the second (located opposite the first tool).

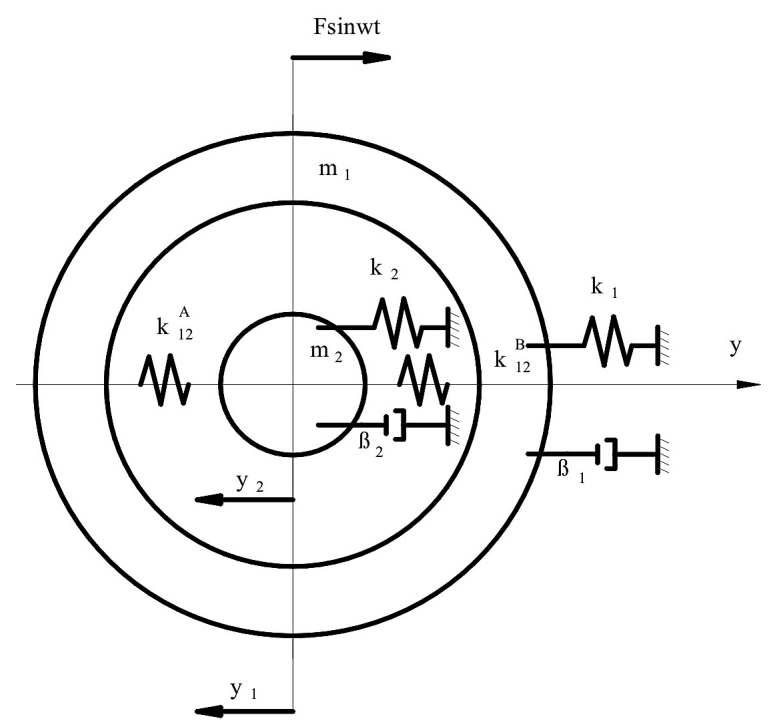

Fig. 1. Mechanical two-mass model of the OUPN system while chambering

Bonding ratio (machining rigidity) was defined analytically $[1,7,2]$. Machining process is described by means of a spring with rigidity ratio $k_{12}=k b$, where $k=\sigma_{0} \xi_{0}$ - the relative machining force (with reference to the machined surface), $\xi$ - chip shrinkage, $b$ - the width of the machined layer. The width of the machined layer is the function of machining depth $b=a_{\mathrm{p}} / \operatorname{tg} K_{\mathrm{r}}$, where $K_{\mathrm{r}}-$ the main approach angle. $k_{12}$ goes from maximum to minimum during a half-turn in the first parting-off tool and from min to max in the second tool. The dynamic component of machining forces at the opposite parting-off tools, conditioned by the changing surplus brought about in the turning phase of the semi-manufactured product, are in the opposite phases.

$$
k_{12}^{A} y \sin \omega t=-k_{12}^{B} y \sin (\omega t+\pi),
$$

where: $\omega$ - angular part of the surplus change equal to the frequency of the part's revolution,

$\pi$ - delay phase of machining force at the opposite parting-off tools,

$y$ - surplus eccentricity.

Summary component of machining radial force $\Delta F_{y}=F_{y}{ }^{A}-F_{y}{ }^{B}$ changes with frequency $\omega$. Displacement of the semi-manufactured product leads to the change of machining force with delay $\tau$. In accordance with the dynamic model (Fig. 1) a mathematical model was developed. The model is a system 
of quadratic heterogeneous differential equations with constant coefficients.

$$
\begin{gathered}
m_{1} \ddot{y}_{1}+\beta_{1} \dot{y}_{1}+k_{1} y_{1}+2 k_{12}\left(y_{1}-y_{2}\right)=F(t)+F_{1}(t)+F_{2}(t) \\
m_{2} \ddot{y}_{2}+\beta_{2} \dot{y}_{2}+k_{2} y_{2}-2 k_{12}\left(y_{1}-y_{2}\right)=0,
\end{gathered}
$$

where: $y_{1}-y_{2}=x_{1}^{A}, y_{2}-y_{1}=x_{2}^{B}$ - relative displacement of a part and a tool on a parting-off tool $\mathrm{A}$ and $\mathrm{B}$ (a change in the thickness of the machined layer);

$F(t) ; F_{1}(t) ; F_{2}(t)$ - periodic forces operating as a result of imbalance of revolving parts transferred by the base and the component variables of the machining force.

After the relative displacement of the semi-manufactured product and the tool, machining depth changes equally on both parting-off tools in accordance with the largeness and the opposite, in accordance with the range of $\left(x_{1}^{A}=-x_{2}^{B}\right)$. From the point of view of physics, double parting-off tool machining is characterized with a double displacement resistance $x_{1,2}$. Delays in the change of machining force at a relative displacement of a part and tool can be disregarded due to the low time constant of the elastic system $(t=0,003 \mathrm{~s})$ in comparison with the semi-manufactured product's revolution time $(t=0,1 \mathrm{~s})$ conditioning the change of the removed surplus. The expression $2 k_{12}\left(y_{1}-y_{2}\right)$ may be considered as the quasistatic characteristic of machining process. Force $F(t)$ which changes in a sinusoid manner was assumed as the fundamental external interference.

In case of a tool with guide bars, rigidity and absorbency ratios of the tool-support sub-system (PNS) are defined by a connection reaction of linking bars with the surface of the machined hole $k_{3}$ and $\beta_{3}$. After simplifying the equation it assumes the following form:

$$
\begin{gathered}
m_{1} \ddot{y}_{1}+\beta_{1} \dot{y}_{1}+k_{1} y_{1}+2 k_{12}\left(y_{1}-y_{2}\right)=F(t), \\
m_{2} \ddot{y}_{2}+\beta_{3} \dot{y}_{2}+k_{3} y_{2}-2 k_{12}\left(y_{1}-y_{2}\right)=0 .
\end{gathered}
$$

The technological system was examined analytically.

\section{ANALYTICAL STUDY OF THE TECHNOLOGICAL SYSTEM OF DEEP HOLES CHAMBERING}

An analytical study of the technological system in machining process was carried out in order to justify the minimization of relative vibrations' amplitude as a result of automatic control of OUPN parameters.

The following variables were introduced:

$$
x_{1}=y_{1}-y_{2} ; x_{2}=y_{1}+y_{2} ; y_{1}=1 / 2\left(x_{1}+x_{2}\right) ; y_{2}=1 / 2\left(x_{2}-x_{1}\right) \text {. }
$$

Right and left parts of equations were divided respectively by $m_{1}$ and $m_{2}$

$$
\begin{aligned}
& 1 / 2\left(\ddot{x}_{1}+\ddot{x}_{2}\right)+\beta_{1} /\left(2 m_{1}\right)\left(\dot{x}_{1}+\dot{x}_{2}\right)+k_{1} /\left(2 m_{1}\right)\left(x_{1}+x_{2}\right)+k_{12} /\left(2 m_{1}\right) x_{1}=F_{0} \sin \omega t, \\
& 1 / 2\left(\ddot{x}_{2}-\ddot{x}_{1}\right)+\beta_{2} /\left(2 m_{2}\right)\left(\dot{x}_{2}-\dot{x}_{1}\right)+k_{2} /\left(2 m_{2}\right)\left(x_{2}-x_{1}\right)-k_{12} /\left(2 m_{2}\right) x_{2}=0 .
\end{aligned}
$$

Both first and second equation were solved. Constant coefficients were grouped as regards new variables, new designations were introduced::

$$
\begin{aligned}
& r_{1}=\frac{1}{2}\left(\frac{\beta_{1}}{m_{1}}+\frac{\beta_{2}}{m_{2}}\right) ; \quad r_{2}=\frac{1}{2}\left(\frac{\beta_{1}}{m_{1}}-\frac{\beta_{2}}{m_{2}}\right), \\
& c_{1}=\frac{1}{2}\left(\frac{k_{1}}{m_{1}}+\frac{k_{2}}{m_{2}}\right) ; \quad c_{2}=\frac{1}{2}\left(\frac{k_{1}}{m_{1}}-\frac{k_{2}}{m_{2}}\right), \\
& c_{3}=\frac{k_{\mathfrak{L}}}{m_{1}}+\frac{k_{\mathfrak{L}}}{m_{2}} \quad c_{4}=\frac{k_{\mathfrak{L}}}{m_{1}}-\frac{k_{\mathfrak{P}}}{m_{2}} \quad P=\frac{F_{0}}{m_{1}} .
\end{aligned}
$$


The following solution was obtained

$$
x_{1}=z_{1} e^{-i \omega t} ; x_{2}=z_{2} e^{-i \omega t},
$$

where: $z_{1}(\omega)=z_{0} e^{i K r}=z_{0} \cos K_{r}+z_{0} \sin K_{j}$,

$j$-linearized rigidity coefficient.

Substituting the solution obtained in (6) and differentiating it with $x_{1}$ and reducing it by $e^{-i \omega t}$ the following was obtained:

$$
\begin{gathered}
\left(-\omega^{2}-r_{1} \omega j+c_{1}+c_{3}\right) x_{1}+\left(c_{2}-r_{2} \omega j\right) x_{2}=P, \\
\left(-r_{2} \omega_{0}{ }^{2} i+c_{2}+c_{4}\right) x_{1}+\left(c_{1}-\omega^{2}-r_{1} \omega j\right)_{x_{2}}=P .
\end{gathered}
$$

System determinant

$$
\Delta=\left|\begin{array}{l}
-\omega^{2}-r_{1} \omega j+c_{1}+c_{3} \cdots c_{2}-r_{2} \omega j \\
-r_{2} \omega_{o}{ }^{2} i+c_{2}+c_{4} \cdots \cdot c_{1}-\omega^{2}-r_{2} \omega i
\end{array}\right| .
$$

where: $z \leq c ; \Delta=\omega^{4}+\left(2 c_{1}-c_{3}\right) \omega^{3}+c_{1}^{2}-c_{2}^{2}+c_{1} c_{3}-c_{2} c_{4}$.

In accordance with Cramer's systems,

$$
\begin{gathered}
X_{1}=\frac{\Delta x_{1}}{\Delta}= \\
=\frac{P\left(c_{1}-c_{2}-\omega^{2}\right)+\left(\operatorname{Pr}_{2} \omega-\operatorname{Pr}_{1} \omega\right) j}{\omega^{4}+\left(r_{2}^{2}-r_{1}^{2}-c_{3}-2 c_{1}\right)+c_{1}^{4}-c_{2}^{2}+c_{1} c_{3}+c_{2} c_{4}+\left(2 r_{1} \omega^{3}-2 r_{1} c_{1} \omega+2 c_{2} r_{2} \omega-c_{2} r_{1} \omega+c_{1} r_{2} \omega\right) j}
\end{gathered}
$$

(9) can be presented as

$$
X_{1}=\frac{A C+B D}{C^{2}+D^{2}}+\frac{B C-A D}{C^{2}+D^{2}} j
$$

where: $A=P \frac{k_{2}}{m_{2}-\omega^{2}} ; B=P d \omega ; C=r_{1}-r_{2}, D=2 r_{1} \omega^{3}+\frac{d k_{1} \omega}{m_{1}}+\frac{d k_{2} \omega}{m_{2}}+k_{12} \omega\left(\frac{d}{m_{1}}-\frac{d}{m_{2}}\right)$;

$$
d=2 m_{1}^{2}-\frac{1}{2 m_{1} m_{2}} \text {. }
$$

The solution in the form of $z_{1}=z_{0} \cos \left(\omega t-K_{j}\right)$ is sought, where $z_{0}^{2}=\frac{A^{2}+B^{2}}{C^{2}+D^{2}}$.

Expressing $z_{0}$ by constant coefficients the following was obtained:

$$
x_{1}^{2}=z_{0}^{2}=\frac{P\left(\lambda_{2}-\omega^{2}\right)+P^{2} d^{2} \omega^{2}}{\left.\left\{\left(\lambda_{1}-\omega^{2}+e k_{12} m_{2}\right) \lambda_{2}+d \lambda_{1}^{2} k_{12} m_{1}+\lambda_{1} \omega^{2}-f k_{12} \omega^{2}+\omega^{4}\right]+\left(2 r_{1} \omega^{2}+d \lambda_{1} \omega+k_{12} g \omega+d \lambda_{2} \omega\right)\right\}^{2}}
$$

The following designations were introduced

$$
\begin{gathered}
\lambda_{1}-\omega^{2}+e k_{12} m_{2}=N, \\
d \lambda_{1}^{2} k_{12} m_{1}+\lambda_{1} \omega^{2}-f k_{12} \omega^{2}+\omega^{4}=M, \\
2 r_{1} \omega^{2}+d \lambda_{1} \omega+k_{12} g \omega=L .
\end{gathered}
$$


Then

$$
x_{1}^{2}=\frac{P\left(\lambda_{2}-\omega^{2}\right)+P^{2} d^{2} \omega^{2}}{\left[\left(N \lambda_{2}+M\right)+\left(L+d \lambda_{2} \omega\right)\right]^{2}}
$$

In order to evaluate the solution, equation (12) is differentiated by $\lambda_{2}$ and the numerator is equaled with zero. Roots of the equation $\lambda_{1}$ and $\lambda_{2}$ are defined for $\left(M / N+\omega^{2}=0\right)$ then: $\lambda_{2}-\omega^{2}=0 ; \lambda_{1}+M$ $/ N=0$; hence $\lambda_{2}=\omega^{2} ; \lambda_{1}=-M / N$.

Substituting the obtained roots to (9) the following was obtained

$$
x_{1}=\frac{P_{0}}{M \omega^{2}-M}=0 ; x_{2}=\frac{P\left(M+N \omega^{2}\right)}{N D} .
$$

As a consequence, it was indicated that the relative vibrations amplitude $\mathrm{x}$ is a polynomial function of $\mathrm{M}, \mathrm{N}, \mathrm{D}$, which include both coefficients characterizing system's parameters and machining process.

When OUPN and machining parameters are selected in a particular manner, it can lead to a resonance.

The examination of solutions of the system enables the determination of the influence of absorbency on the relative vibrations amplitude. In order to carry out a numeric analysis of solutions the following coefficients must be determined either experimentally or theoretically: $m_{12}, k, \beta, k_{12}$, $\mathrm{F}_{0}$. Reduced masses of the tool and parts are determined in accordance with the following:

$$
m=\frac{k}{f^{2}} \text {. }
$$

The value of the reduced mass coefficient

$$
K=\frac{\pi F_{0}}{\beta A_{\max }},
$$

where: $A_{\max }$ - resonance amplitude.
Absorbency coefficient is determined in accordance with the width of resonance peak

$$
\beta=\frac{\pi\left(f_{1}-f_{2}\right)}{f} .
$$

Fig. 2 presents the numerical solution of the system of equations. The analysis of the numerical solution indicated that the regulation of relative vibrations amplitude allows for the optimal control of rigidity.

Introduction of absorbency induces a phase shift of the tool and the part. Decreasing amplitude of relative vibrations along with the increase of machining rigidity enables the improvement of precision and efficiency. The lowest amplitude of relative vibrations can only be obtained when own frequency of tool-support sub-system equals the frequency of exciting force. The reduced frequency of tool-support sub-system cannot equal the external interference frequency at the set parameters of OUPN system when rigidity at high yield parameter decreases, which facilitates the reduction of own frequency.

\section{SUMMARY}

While selecting rigidity and absorbency of tool-support sub-system one can control the frequency when the minimum of relative vibrations' amplitude is obtained in radial direction.

As a result of OUPN parameters optimization, the transition processes time can be reduced, dynamic rigidity increased and the level of vibrations reduced. When chambering thin-walled holes in sleeves, the rigidity of both part-support and tool-support sub-systems ought to be controlled in order to minimize the amplitude of relative vibrations.

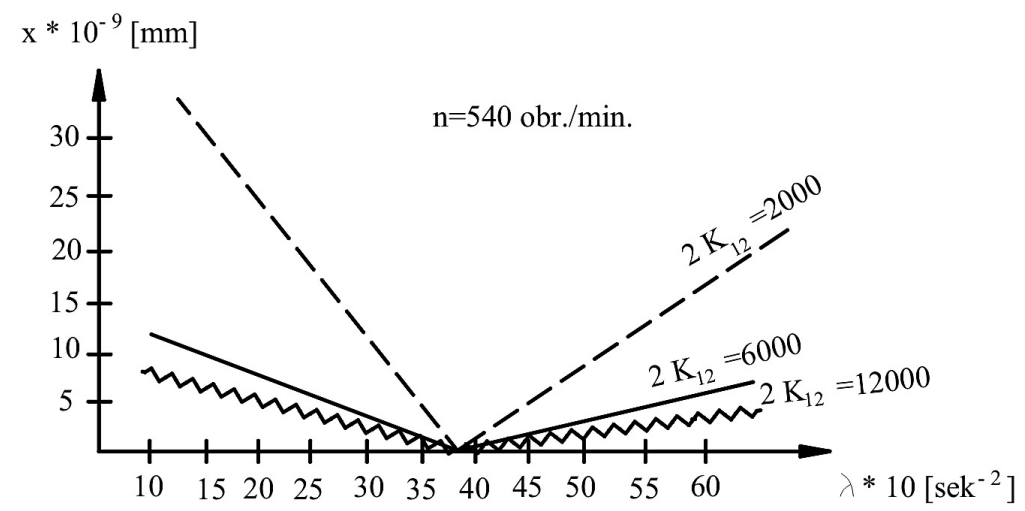

Fig. 2. Numerical solution of the system of equations 


\section{REFERENCES}

1. Draczew O., Hałas W., Taranenko G., Taranenko W.: Sterowanie obróbką wibracyjną wałów o małej sztywności. Pomiary. Automatyka. Robotyka, no 2, 2008.

2. Fu H., Zhang L.: The model and experimental study for vibration control in deep-hole boring. $20112^{\text {nd }}$ International Conference on Mechanic Automation and Control Engineering, MACE 2011-Procedings, art. no. 5988464, pp. 6239-6242.

3. Szot T., Świć A.: Badania teoretyczne roztaczania otworów głębokich. W monografii Zastosowania informatyki w inżynierii produkcji. Lubelskie Wydawnictwo Naukowe, Lublin 2009, pp. 93-104.
4. Szot T., Świć A.: Kształtowanie otworów głębokich narzędziem o zmiennej sztywności. Modele inżynierii teleinformatyki. Wybrane zagadnienia 3. Koszalin 2009, pp. 50-57.

5. Świć A.: Technologia obróbki otworów o małej sztywności. Wydawnictwo Politechniki Lubelskiej, Lublin 2007.

6. Świć A, Taranenko W, Szabelski J.: Modelling dynamic systems of low-rigid shaft grinding. Eksploatacja i Niezawodność - Maintenance and Reliability, 2(50), 2011, pp. 13-24.

7. Taranenko V., Świć A.: Urządzenia sterujące dokładnością obróbki części maszyn o małej sztywności. Wydawnictwo Politechniki Lubelskiej, Lublin 2006. 